\title{
Biodiversity of Root Endophytic Fungi from Oxyria sinensis Grown in Metal-Polluted and Unpolluted Soils in Yunnan Province, Southwestern China
}

\author{
Meiyan Zhu ${ }^{1,2} \mathbb{D}$, Yanhua Ding ${ }^{1,2}$, Xuejiao Li ${ }^{1,2}$, Yuqing Xiao ${ }^{1,2}$, Zhiwei Zhao ${ }^{1, *(D)}$ and Tao Li ${ }^{1, *}$ \\ 1 State Key Laboratory for Conservation and Utilization of Bio-Resources in Yunnan, Yunnan University, \\ Kunming 650091, China; zhumeiyan93@126.com (M.Z.); dingyanhua09@163.com (Y.D.); \\ lixuejiao0903@163.com (X.L.); xiaoyuqing@mail.ynu.edu.cn (Y.X.) \\ 2 School of Life Sciences, Yunnan University, Kunming 650500, China \\ * $\quad$ Correspondence: zhaozhw@ynu.edu.cn (Z.Z.); litao@ynu.edu.cn (T.L.); Tel.: +86-871-6503-4838 (Z.Z.)
}

check for updates

Citation: Zhu, M.; Ding, Y.; Li, X.; Xiao, Y.; Zhao, Z.; Li, T. Biodiversity of Root Endophytic Fungi from Oxyria sinensis Grown in

Metal-Polluted and Unpolluted Soils in Yunnan Province, Southwestern China. Plants 2021, 10, 2731. https:// doi.org/10.3390/plants10122731

Academic Editors: Shawkat Ali and Joey Brent Tanney

Received: 18 November 2021 Accepted: 8 December 2021 Published: 11 December 2021

Publisher's Note: MDPI stays neutral with regard to jurisdictional claims in published maps and institutional affiliations.

Copyright: (c) 2021 by the authors. Licensee MDPI, Basel, Switzerland. This article is an open access article distributed under the terms and conditions of the Creative Commons Attribution (CC BY) license (https:// creativecommons.org/licenses/by/ $4.0 /)$.

\begin{abstract}
Oxyria sinensis adopts a tolerant strategy as a metal excluder to survive toxic metal concentrations. Biodiversity and the endophytic fungal community colonizing the $O$. sinensis roots were assessed from a mining area (MA) and a neighboring non-mining area (nMA) in southwestern China. All O. sinensis roots formed fully developed dark septate endophytes (DSEs) and arbuscular mycorrhizal fungi (AMF). Total DSE colonization was higher for the MA versus nMA, in contrast to the total AMF colonization in the two sites. The DSE colonization was higher than AMF colonization regardless of the site. Pure-culture data showed that the fungi closely related to Exophiala, Cadophora and Phialophora dominantly colonized the $O$. sinensis roots. A total of 450 operational taxonomic units (OTUs) were identified showing the presence of a distinct fungal community in MA and nMA, which was shaped by soil physiochemical properties, including soil Zn concentrations and organic matter. We found that $O$. sinensis accumulates and adapts efficiently to local endophytic fungi to achieve the expansion of its community, including the spontaneously reclaimed DSE. This property may be targeted to achieve its colonization with a pioneer plant for phytoremediation in the restoration of a vegetation cover in a metal-contaminated area.
\end{abstract}

Keywords: Oxyria sinensis; dark septate endophyte (DSE); arbuscular mycorrhizal fungi (AMF); diversity; metal contamination

\section{Introduction}

Soil metal pollution is a global concern, due to its high toxicity to various living organisms. This is especially true for barren mining/smelting areas with excessive leaching of heavy metals $[1,2]$. A successive vegetation cover can provide the necessary surface stability to reduce the dispersion of contaminants via eolian spread and water erosion. Meanwhile, vegetative technologies such as phytoremediation are increasingly recognized as costeffective and ecologically sound alternatives to metal-polluted land rehabilitation [3,4].

Heavy-metal-contaminated soils suffer from macronutrient and substrate deficiencies, limiting the option of revegetation, which is an otherwise ideal approach for remediation $[5,6]$. A growing body of literature from both field and greenhouse experiments provides evidence that root-associated endophytes, e.g., the most commonly encountered dark septate endophytes (DSEs) and arbuscular mycorrhizal fungi (AMF), do indeed aid some specific plants in adapting and resisting a wide range of biotic and abiotic environmental stresses [6,7]. For example, Hui et al. report that the colonization of a root-associated endophytic fungus of Sebacinales, Serendipita (=Piriformospora) indica, confers cadmium (Cd) tolerance to Nicotiana tabacum in hydroponics, pot and field trials [8]. Previous data from greenhouse experiments show that the colonization of maize roots with DSE was associated with an increased $\mathrm{Cd}$ tolerance, significantly less phytotoxicity and enhanced plant 
growth [9]. Subsequent field trials showed evidence of an increased plant survival rate in mine spoils due to root colonization with mycorrhizal fungi, e.g., three Acacia species, Pinus sylvestris $[10,11]$. Additionally, diverse and multifunctional root-associated endophytes are believed to be major determinants of plant community structure in early succession $[12,13]$ and enhance plant establishment in contaminated soils [10,14]. Long-term studies were carried out by Veselkin et al. [15], spanning 1978-2006 to evaluate the succession of vegetation on different parts of overburdened rocks in Karaganda, Kazakhstan. The authors noted that the association of obligate species with AMF during the revegetation phase led to enhanced species diversity. The mycorrhizal plants' accelerated revegetation and reclamation were suggested to involve different strategies, such as amelioration and adaptation, which subsequently encouraged the establishment and vegetation development. In addition, the synergistic interactions between plants and the root-associated endophytes led to better nutrient and water access by stimulating initial growth and improving plant biomass production, thereby enhancing the rate of remediation of contaminated soil [16]. Overall, root fungal bioaugmentation, in combination with plant reclamation represents an attractive approach for the decontamination of soils polluted with heavy metals [6].

There are many ancient and abandoned slag heaps of non-ferrous metals from mining in Yunnan province, southwestern China, and successive vegetation covers have been established spontaneously in these slags at different times. These indigenous plants are potential reservoirs of germplasm for phytoremediation purposes [17,18], as these are not only tolerant to the stressed environment but are also adapted to the prevailing local climate conditions. Among these, an herb species native to the Himalayas known as Oxyria sinensis (Polygonaceae) has attracted a lot of attention for potential revegetation, due to its high metal tolerance and the ability to generate considerable biomass, as well as the more easily accessible sexual seeds and asexual rhizomes $[19,20]$. Interestingly, $O$. sinensis adopts a tolerant strategy as a metal excluder to survive in toxic metal concentrations presented in the growth medium [21]. However, there is little knowledge about the interactions between $O$. sinensis and their root-associated endophytic fungi, which are actively effective for the integral role in response to heavy metals. Our work aims to determine the colonization characteristics and community structure of root-associated endophytic fungi from both mining and non-mining ecotypes of $O$. sinensis, using pure-culture and culture-independent methods. In addition, we aimed to explore the potential functional roles of endophytic fungi in enhancing their host plant tolerance/adaptation against metal stress and the potential restoration abilities of $O$. sinensis in the Yunnan unclaimed mining area, China.

\section{Results}

\subsection{Chemical Properties of the Soil}

The physiochemical properties of the soil from the Kuangshan mining area (MA) differed from those of the non-mining area (nMA). The soil from the mining area had significantly higher concentrations of $\mathrm{Pb}, \mathrm{Zn}$ and $\mathrm{Cd}$ compared to the non-mining area and contained $191.9 \pm 37.67 \mathrm{mg} \mathrm{kg}^{-1} \mathrm{~Pb}, 719.5 \pm 210.00 \mathrm{mg} \mathrm{kg}^{-1} \mathrm{Zn}$ and $1.9 \pm 0.51 \mathrm{mg} \mathrm{kg}^{-1} \mathrm{Cd}$, respectively. Similarly, there was a significantly higher organic matter content in MA, but a markedly lower content of available $\mathrm{P}\left(19.7 \pm 0.84 \mathrm{mg} \mathrm{kg}^{-1}\right.$ in MA vs. $26.1 \pm 1.06 \mathrm{mg} \mathrm{kg}^{-1}$ in nMA) $(p<0.05)$. There was no significant difference in the alkaline hydrolysis $\mathrm{N}$ or the available $\mathrm{K}$ and soil $\mathrm{pH}$ for both areas (Table 1 ).

\subsection{DSE and AMF Colonization}

Root samples from both areas (MA and nMA) showed the presence of typical AMF structures, i.e., arbuscules, hyphal coils and vesicles, as well as DSE structures such as dark septate hyphae and microsclerotia (Figure 1). For both areas, we found that there was a higher DSE colonization than that of AMF in the roots of $O$. sinensis, and this was especially true for MA samples with a significantly higher DSE colonization $(p<0.01)$. Furthermore, we also observed that metal pollution of MA soil significantly inhibited the AMF colonization, and AMF colonization intensity in the nMA was markedly higher 
than its mining counterpart $(p<0.05)$, while DSE colonization exhibited a reverse trend (Figure 2). AMF and DSE colonization were $2.90 \pm 0.55 \%$ and $11.46 \pm 1.87 \%$ in the MA area and $6.28 \pm 1.00 \%$ and $8.97 \pm 1.39 \%$ in the $\mathrm{nMA}$ area, respectively.

Table 1. Comparison of the physiochemical properties and lead $(\mathrm{Pb})$, zinc $(\mathrm{Zn})$ and cadmium $(\mathrm{Cd})$ concentrations in the rhizosphere soil samples from both mining (MA) and non-mining (nMA) areas in Yunnan Province, southwestern China (means $\pm \mathrm{SE}, n \geq 3$ ).

\begin{tabular}{|c|c|c|c|c|c|c|c|c|}
\hline \multirow{2}{*}{ Sites } & \multicolumn{5}{|c|}{ Physiochemical Properties (mg kg-1) } & \multicolumn{3}{|c|}{ Total Metal Concentration (mg kg ${ }^{-1}$ ) } \\
\hline & $\begin{array}{c}\text { Alkaline } \\
\text { Hydrolysis N }\end{array}$ & $\begin{array}{l}\text { Organic } \\
\text { Matter }\end{array}$ & Available P & Available K & pH & $\mathrm{Pb}$ & $\mathrm{Zn}$ & Cd \\
\hline MA & $60.4 \pm 13.10$ & $16.9 \pm 3.47 b$ & $19.7 \pm 0.84 \mathrm{a}$ & $184.9 \pm 25.03$ & $6.2 \pm 0.06$ & $191.9 \pm 37.67 b$ & $719.5 \pm 210.00 \mathrm{~b}$ & $1.9 \pm 0.51 \mathrm{~b}$ \\
\hline nMA & $42.5 \pm 2.80$ & $5.3 \pm 0.72 \mathrm{a}$ & $26.1 \pm 1.06 \mathrm{~b}$ & $232.0 \pm 8.18$ & $6.2 \pm 0.03$ & $31.9 \pm 3.87 \mathrm{a}$ & $192.5 \pm 25.40 \mathrm{a}$ & $0.0 \pm 0.00 \mathrm{a}$ \\
\hline
\end{tabular}

Different letters mean significant differences according to $t$-test $(p<0.05)$.

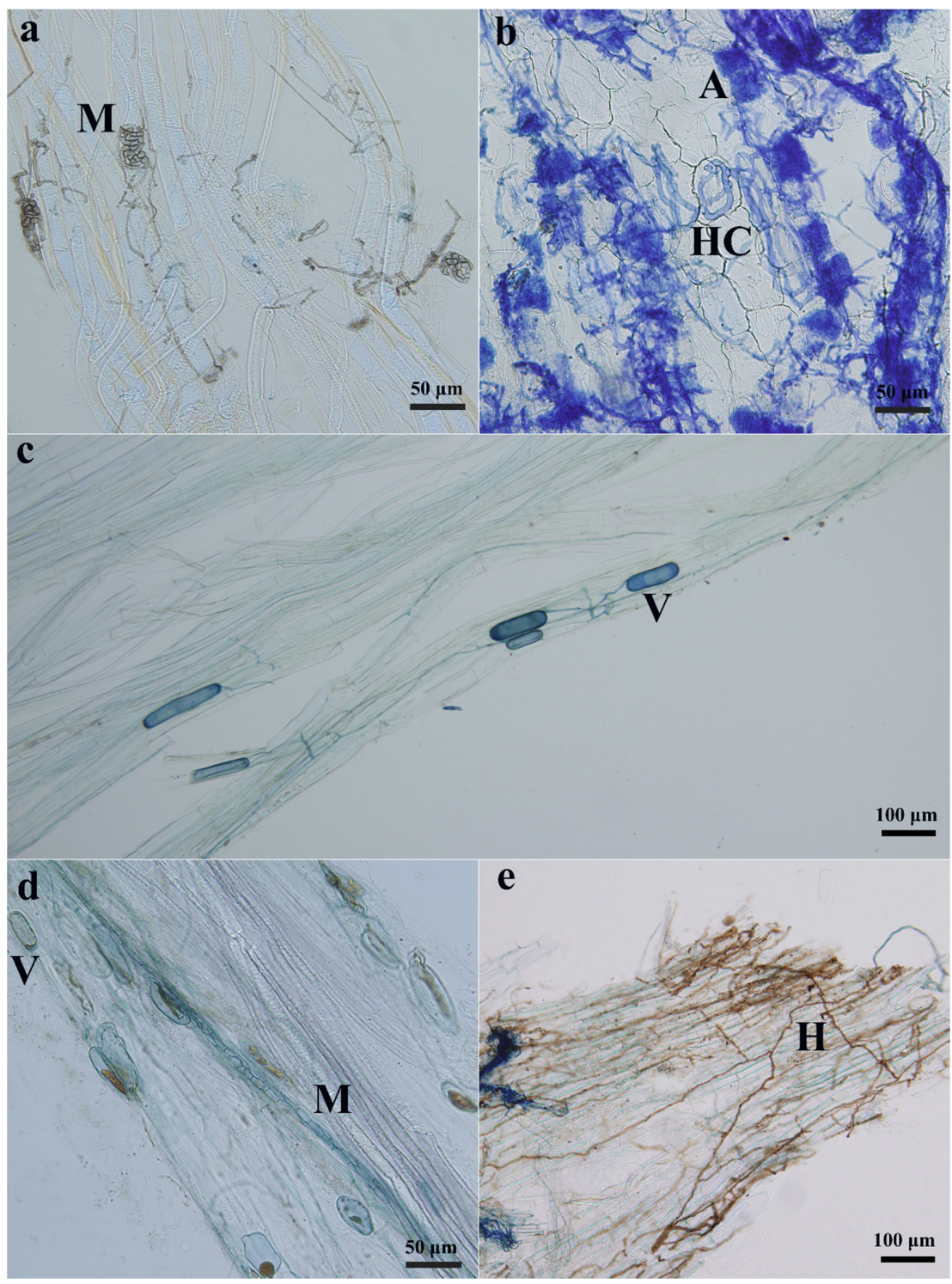

Figure 1. Microscopic examination of morphological characteristics of DSE and AMF root colonizers of $O$. sinensis from mining area (MA) $(\mathbf{a}-\mathbf{c})$ and non-mining area (nMA) $(\mathbf{d}, \mathbf{e})$ in Yunnan Province, southwestern China. Microsclerotia $(\mathrm{M})(\mathbf{a}, \mathbf{d})$ and hyphae $(\mathrm{H})$ (Figure 1e) of DSE structures and vesicles (V) (c,d), arbuscules (A) (b) and hyphal coils (HC) (b) of AMF structures are visible in the micrograph. 


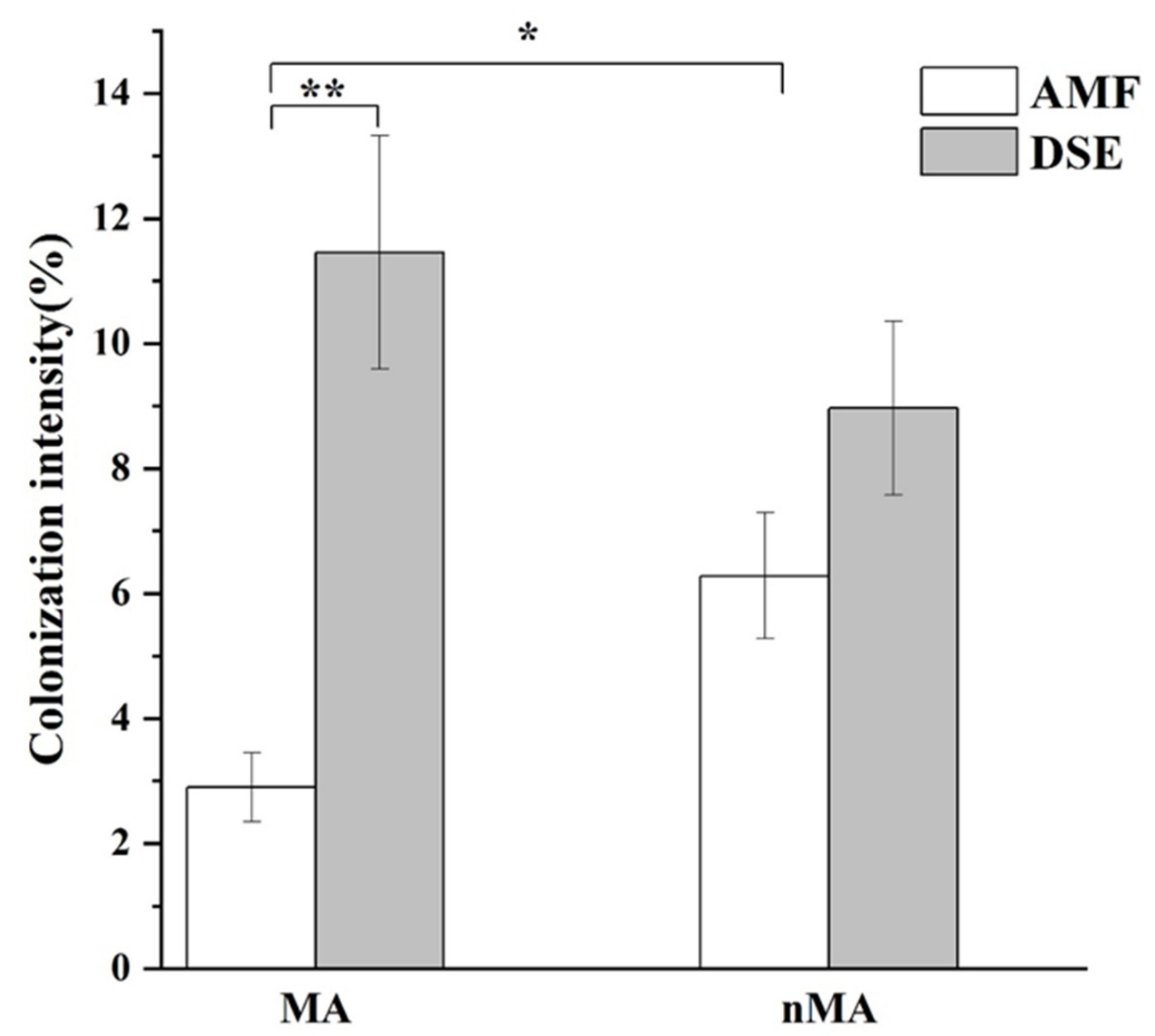

Figure 2. The total colonization intensity of DSE and AMF in the roots of $O$. sinensis from MA and nMA areas in Yunnan Province, southwestern China (means $\pm \mathrm{SE}, n \geq 10$ ). ${ }^{*}$ Indicates significant differences between two groups $\left(t\right.$-test, $\left.{ }^{*} p<0.05,{ }^{* *} p<0.01\right)$.

\subsection{DSE Isolation and Identification}

A total of 48 root-associated melanized fungi were isolated from the roots of $O$. sinensis, including 29 and 19 strains isolated from the non-mining and mining ecotypes, respectively. According to phylogenetic analysis, these fungal strains were clustered into fourteen phylogenetic groups, including five MA-specific clades, four nMA-specific clades and five clades overlapped in both areas (Figure 3). We also found that the majority of the isolates were closely related to fungal members of Cadophora, Phialophora, Leptodontidium and Exophiala, and the most dominant fungal strains belonged to the clades of Helotiales, Chaetothyriales, Ascomycota and Exophiala, accounting for an approximate total relative abundance (RA) of $60 \%$ (Figure 3). The relative abundance of other several clades, including Minimelacolocus, Pyrenochaeta, Acrocalymma, Sordariomycetes 2 and Pleosporales were also above 4\%, but the species related to Magnaporthaceae, Tetraploshaeria and Lophiostomataceae had the lowest proportions. 


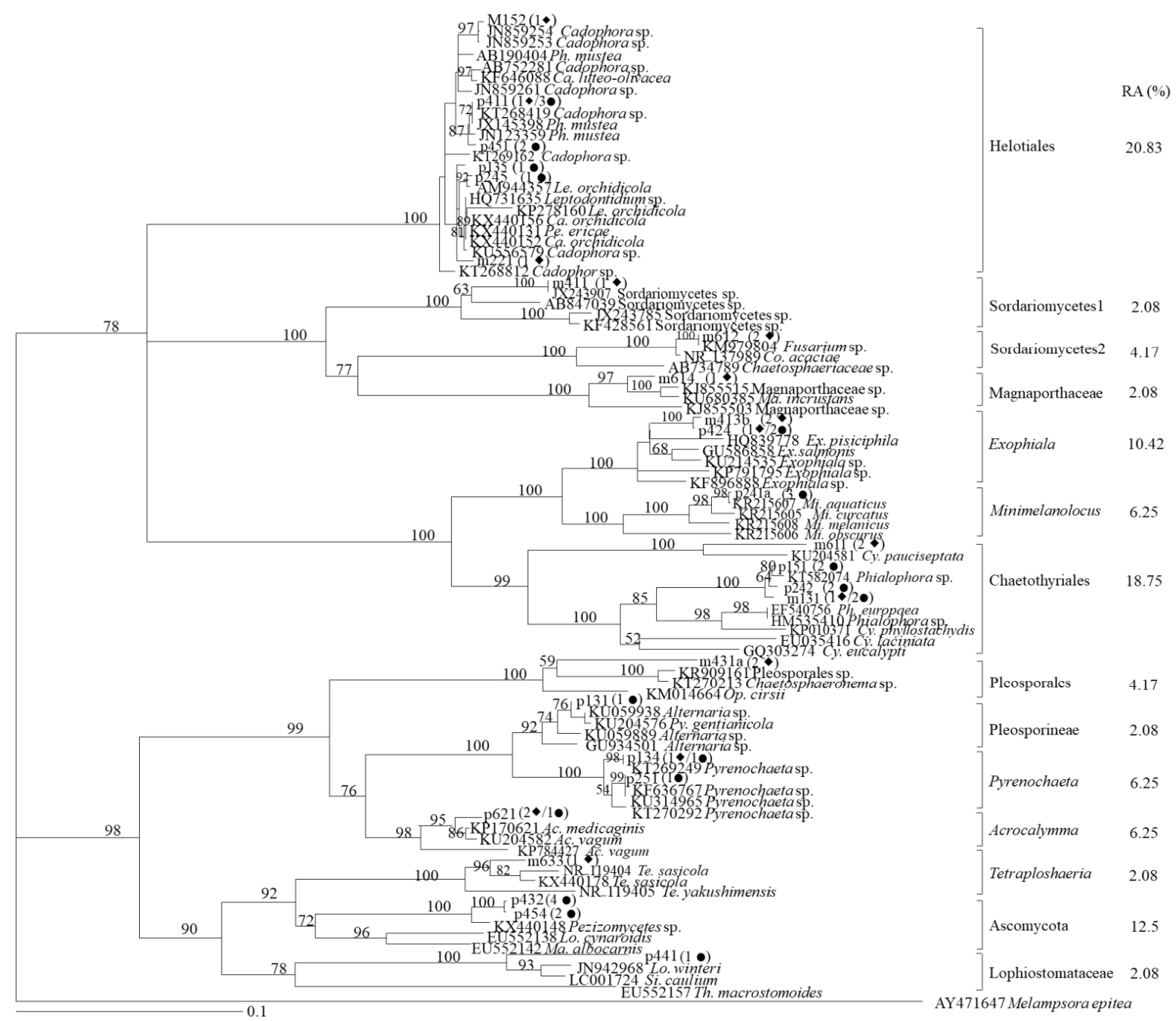

Figure 3. Molecular phylogeny of ITS sequences of melanized fungal isolates from the roots of $O$. sinensis grown in Huize MA and nMA areas in Yunnan Province, southwestern China. $\downarrow$ and $\bullet$ in parentheses mean the numbers of fungal strains isolated from the MA and nMA, respectively, and the relative abundance (RA) of each clade was calculated. Numbers above the nodes denote 1000 bootstrap support in neighbor-joining analysis.

\subsection{Endophytic Fungi Diversity and Community Structure in O. sinensis Roots}

In this study, 345 and 313 fungal operational taxonomic units (OTUs) colonizing the roots of $O$. sinensis from the MA and nMA were found, respectively. There were 208 shared OTUs, which accounted for a proportion of $60.29 \%$ and $66.45 \%$ in MA and nMA, respectively (Figure 4). The OTUs' abundance change curve flattened when the sequencing depth was increased, showing that the data covered the majority of the bioinformatic information about root endophytic fungi (Figure 5). The 'richness' (Chao1 and ACE) and 'evenness' (Shannon and Simpson) of the dominant broad fungal groups were calculated (Table 2). O. sinensis in MA had a greater tendency for richness, while no significant differences in evenness were observed between MA and nMA.

The endophytic fungi community structure (genus level) of $O$. sinensis from MA was richer than in nMA. Xylaria displayed the highest relative abundance at genus level, accounting for $63.5 \%$ and $79.8 \%$ in MA and nMA, respectively. This was followed by the fungi of Magnaportiopsis, Pleeosporales, Ascomycota, Sparassis and Llyonectria in MA. However, these fungal members had less than $0.5 \%$ relative abundance in nMA (Figure 6). Subsequently, the fungal community structures in the O. sinensis roots from MA and nMA were examined using Principal Coordinate Analysis (PCoA). It was performed based on the unweighted Unifrac distance matrixes, and the two axes maximally reflected $47.50 \%$ of the 
total difference (PC1, 29.17\%; PC2, 18.33\%) (Figure 7). Interestingly, the fungal communities in the roots of $O$. sinensis in MA were distinct from their nMA counterparts. Spearman's correlation analysis showed that environmental factors highly correlated with species abundance (Figure 8); e.g., available 'OM' (organic matter), and Zn had a close correlation with seven and eight fungal genera, respectively, followed by $\mathrm{Cd}$ (six genera), available $\mathrm{K}$ (five genera), available $\mathrm{P}$ (four genera) and $\mathrm{Pb}$ (four genera) and available $\mathrm{N}$ (one genus). The number of environmental factors corelating with fungal abundance was in the following order. Fungi belonging to un-s-Trechisporales sp. correlated with six environment factors, followed by Un-s-Ceratobasidiaceae (five factors), Un-s-Chaetothyriales (four factors) and three environment factors for the other four fungal taxa (e.g., Tetracladium).

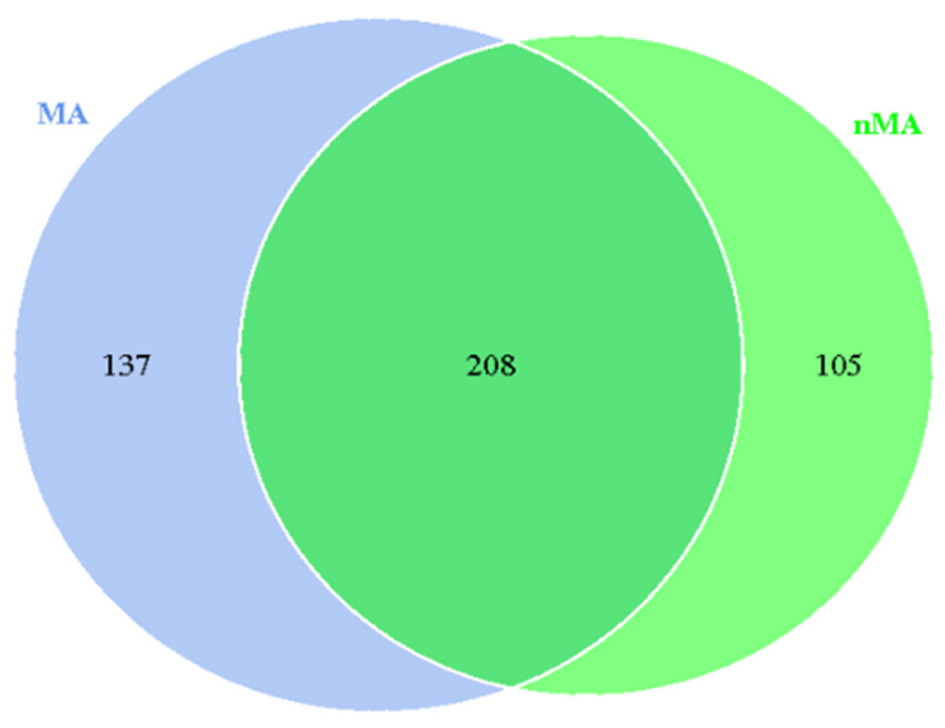

Figure 4. Venn diagram depicting the distribution of endophytic fungi colonizing in the roots of $O$. sinensis in MA and nMA areas in Yunnan Province, southwestern China (OTU level).

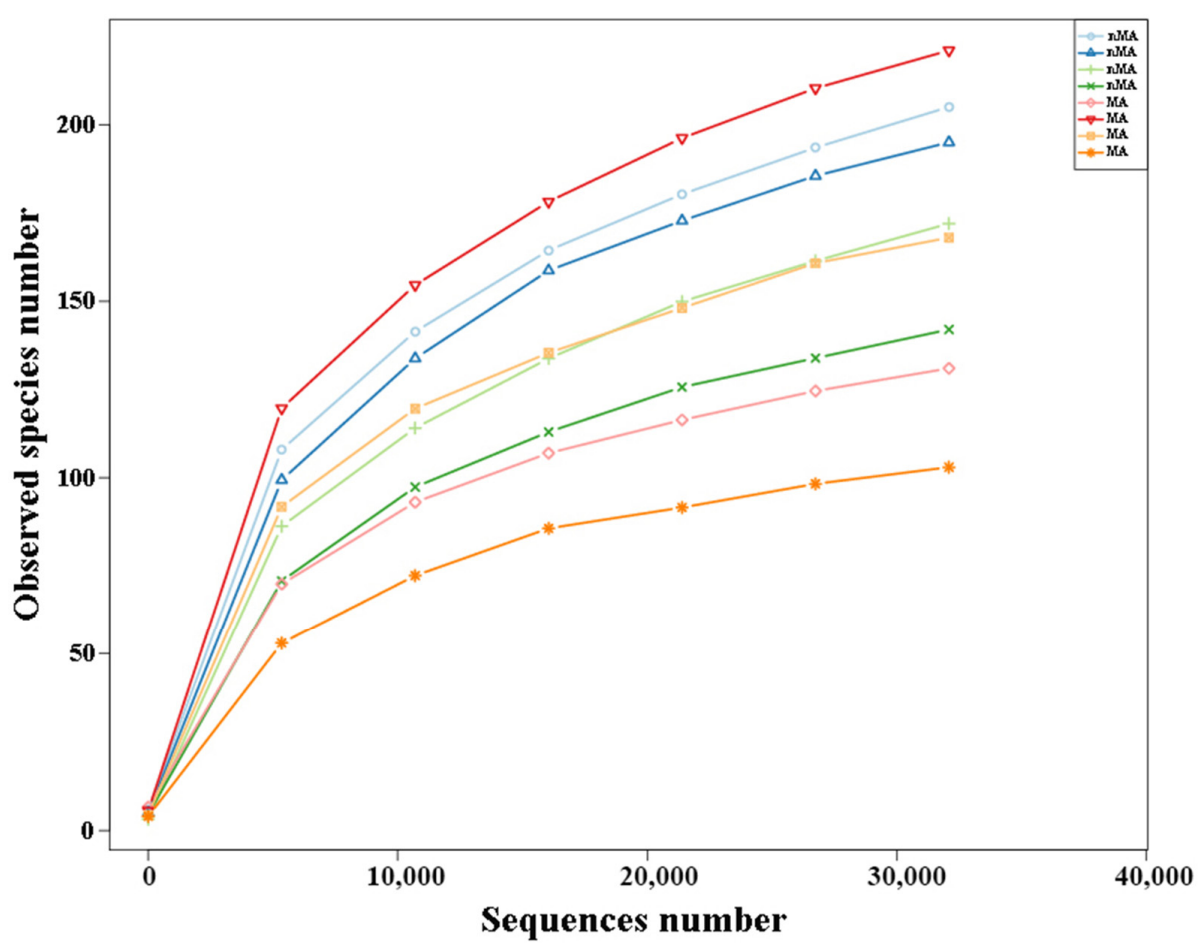

Figure 5. Rarefaction curve of endophytic fungi colonizing $O$. sinensis roots from MA and nMA areas in Yunnan Province, southwestern China. 
Table 2. Diversity indices of endophytic fungi colonizing in the roots of $O$. sinensis from MA and nMA areas in Yunnan Province, southwestern China $(n=4)$.

\begin{tabular}{ccccc}
\hline Sites & ACE & Chao1 & Shannon & Simpson \\
\hline MA & $235.1 \pm 18.23$ & $231.7 \pm 16.21$ & $2.7 \pm 0.31$ & $0.7 \pm 0.08$ \\
nMA & $196.3 \pm 32.88$ & $191.4 \pm 31.70$ & $3.0 \pm 0.22$ & $0.8 \pm 0.04$ \\
\hline
\end{tabular}

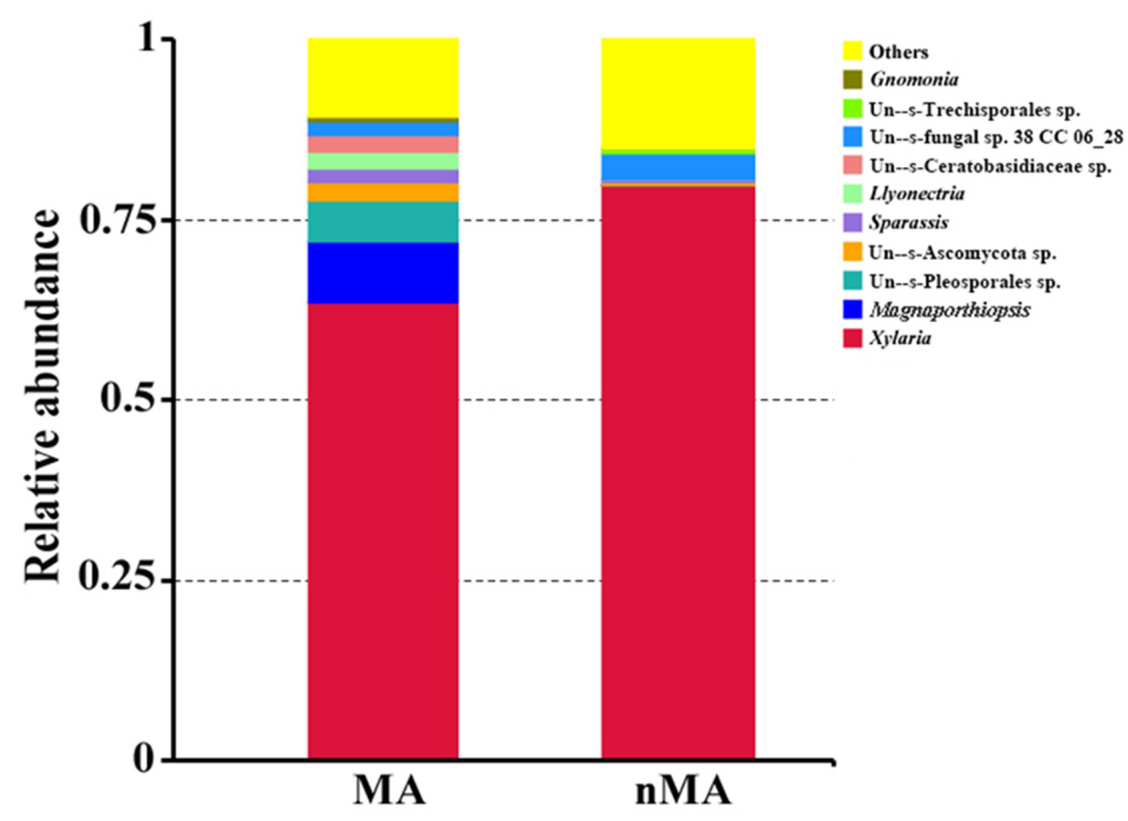

Figure 6. Community composition and relative abundance of endophytic fungi colonizing $O$. sinensis roots of MA and nMA areas in Yunnan Province, southwestern China (genus level).

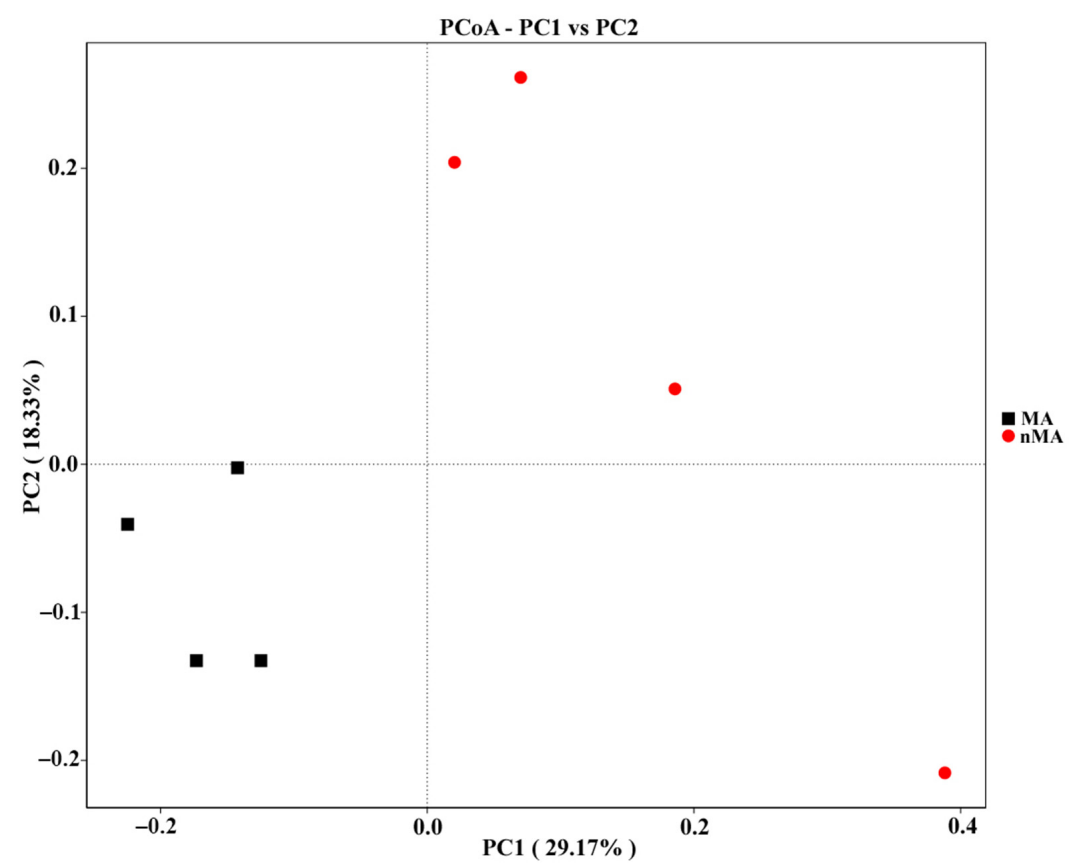

Figure 7. Principal Coordinate Analysis (PCoA) of endophytic fungal community structures in the roots of $O$. sinensis in the MA and nMA areas in Yunnan Province, southwestern China. Each red symbol represents an nMA sample, and each black symbol represents an MA sample. 


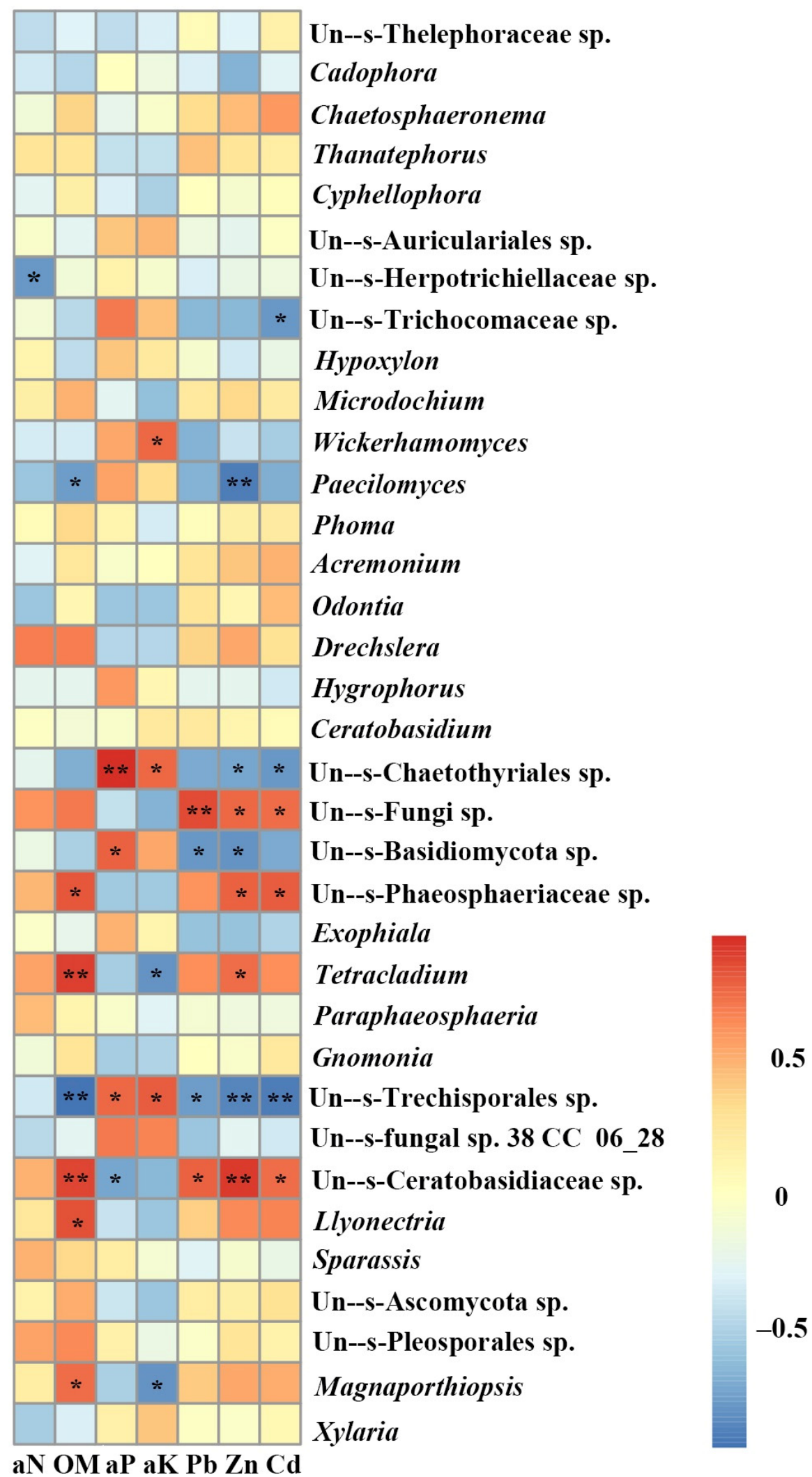

Figure 8. Spearman's correlation analysis between environmental factors and endophytic fungal community structures in the roots of O. sinensis in the MA and nMA areas in Yunnan Province, southwestern China (Genus level). aN, alkaline hydrolysis nitrogen; OM, organic matter; aP, available phosphorus; aK, available potassium. * Indicates a significant correlation between environment factor and endophytic fungi (Spearman correlation analysis, ${ }^{*} p<0.05,{ }^{* *} p<0.01$ ). 


\section{Discussion}

O. sinensis (Polygonaceae) usually grows as a pioneer plant in artificially damaged environments, such as those affected by road construction, damming and mining sites. We observed that both ecotypes of $O$. sinensis growing naturally can form AM structures (hyphae, vesicles and arbuscules) in the roots, and simultaneously lead to the appearance of DSE colonization in large numbers in both MA and nMA. These findings suggest that AMF and DSE are countermeasures for the successful adaptation of the O. sinensis to such environments, with the colonization intensity of DSE being higher than AMF, regardless of the site. Furthermore, the DSE colonization was higher in the MA, while the AMF colonization presented the opposite picture. Ruotsalainen et al. [22] reported similar results in Deschampsia flexuosa, where the colonization intensity of AMF decreased with heavy metal stress, while the DSE colonization showed a slight increase, which was not found to be significant. The colonization of AMF in MA is usually lower than that of in the nMA and may also be related to the tolerance of AMF to heavy metals, as AMF is usually more sensitive to metals than DSE [23]. Gucwa-Prezpióra et al. [24] found that AMF colonization in Plantago major had a negative correlation with the bioavailable contents of heavy metal in the soil, while DSE colonization in Salix caprea was positively correlated with $\mathrm{Pb}$ concentration $[25,26]$. Besides this, it has been suggested that fungal endophytes are not merely mycorrhizal copycats, and DSE has more ecological functions in a stressful environment [6]. Similarly, Vergara et al. [27] reported that DSE contributes to tomato growth by increasing nutrient recovery efficiency, nutrient accumulation and the utilization of organic matter. Leptodontidium orchidicola, a species of DSE, has been claimed to improve tomato quality with an inorganic $\mathrm{N}$ source [28], as well as the enhancing $\mathrm{P}$ absorption by the maize seedlings [29]. Higher DSE colonization intensity in the mining area suggests that DSE may either be an integrated partner for $O$. sinensis to conquer the metal stress or $O$. sinensis is providing a shelter for the DSE in this stressful environment. AMF colonization intensity in the nMA was higher than in the MA, which may correlate with the addition of potassium, which significantly promoted the Lablab purpureus biomass, subsequently reduced heavy metal content and increased the AMF colonization intensity [30].

In this study, we isolated 48 DSE strains from the MA and nMA, and the fungi from the clades of Helotiales, Chaetothyriales and Exophiala were found to be most abundant. Many taxa in Helotiales and Chaetothyriales have been repeatedly noted as DSE fungi [31-33]. For example, our previous research also demonstrated that Exophiala was the dominant DSE fungi in the mining area [34]. Some Exophiala strains, such as E. pisciphila, have an inherently strong tolerance to heavy metals [35] and may also confer metal tolerance to the host plant upon root colonization $[7,36,37]$. We also noted that amongst the 14 fungal clades, only 5 clades consisting of 30 fungal strains (accounting for 62.5\%) were overlapped in both areas, suggesting the environmental variations of soils contributed to the reshaping of rootassociated endophytes. These results were also consistent with the previous findings that the physicochemical factors of metalliferous habitats, as the main physicochemical filters, strongly determine distinctive microbial communities of abandoned tailing dumps [38]. The results obtained by the culture-independent methods showed that Xylaria fungi are one of the most dominant root colonizers, which were reported to initiate endophytic associations with wide host ranges at a global level [39]. Subsequently, Wężowicz et al. [40] found that Xylaria sp. isolated from the roots of Verbascum lychnitis could significantly improve the photosynthesis rates of the plant-endophyte consortia on the post-mining waste dump containing elevated quantities of toxic metals $(\mathrm{Pb}, \mathrm{Zn}$ and $\mathrm{Cd})$.

Presumably, the need to combat severe and complex environmental stresses in the MA necessitates the co-existence of these pioneer plant species with endophytic fungi that can withstand heavy metal stress $[10,11]$. Since the energy and material sources of endophytic fungi were provided by the host plant, it follows that the amount of resources obtained by the host plant directly affects the amount of resources obtained by endophytic fungi. Previously, a study reported that the rate of colonization of a non-mycorrhizal plant, such as Cyperaceae with AMF, positively correlated with the soil $\mathrm{N}$ content and $\mathrm{pH}$, while 
the contents of available $\mathrm{P}, \mathrm{K}$ and organic matter had a negative correlation [41]. In our study, the endophytic fungi of $O$. sinensis in nMA were monotonous, compared to those in the MA. This may suggest that a high level of endophytic fungi species diversity can 'guarantee' plant productivity under different environmental conditions. Other studies also highlighted the positive effect of the species diversity of endophytic fungi on plant productivity and plant coexistence [42,43]. It has been reported that the complementary and selective effects of endophytic fungi lead to increased plant productivity, and that single-inoculation AMF can more effectively maintain the stable growth of plants.

\section{Materials and Methods}

\subsection{Sample Sites and Collection}

Root samples were obtained from an abandoned $\mathrm{Pb}$ and $\mathrm{Zn}$ slag heap (where smelting has been carried out for centuries using traditional methods [44]) with an area of $4 \mathrm{~km}^{2}$ in Huize country, located at $103^{\circ} 42^{\prime} 4^{\prime \prime}$ E, $26^{\circ} 38^{\prime} 5^{\prime \prime} \mathrm{N}$, Yunnan province, southwestern China. For hundreds of years, vegetation was spontaneously established on the spoil heaps, consisting of several pioneer plant species such as Carex inanis and Cyperaceae hebecarpus. Of the perennial herbaceous species, $O$. sinensis dominates the restoration in extremely metal-stressed sites [19].

In these sample sites, both ecotypes of $O$. sinensis from the mining area in Kuangshan and in the neighboring non-mining area (located at a distance of $27.6 \mathrm{~km}$ away) were studied. From each sample site, two sample plot replicates measuring $40 \times 40 \mathrm{~m}^{2}$ were selected, and in total, 20 roots and soil sample repetitions were randomly collected for each O. sinensis ecotype during September 2018.

\subsection{Soil Analysis}

Soil samples (5-25 cm depth) were collected and allowed to air dry at room temperature (RT) for 2 weeks and kept for up to 2 months at RT until further treatment. Samples were milled into a fine powder, and a $0.25 \mathrm{~mm}$ nylon mesh was used to sieve out the larger pieces. Flame atomic absorption spectrometry (TAS-990 spectrophotometer, Beijing Puxi Instrument Factory, Beijing, P.R. China) was used to estimate the levels of $\mathrm{Cd}, \mathrm{Zn}$ and $\mathrm{Pb}$ in soil samples as described previously [36]. As per the literature, the alkali N-proliferation method was used to calculate the alkaline hydrolyzed nitrogen [45], and the potassium dichromate oxidation-outer heating method was used to determine the soil organic matter [46]. Available phosphorus and potassium were calculated by the Olsen method and the ammonium acetate extraction, respectively [47]. The soil $\mathrm{pH}$ was measured using the electric potential method [46].

\subsection{DSE and AMF Colonization}

To assess the DSE and AMF colonization, the roots were adequately washed with running water and subjected to $10 \%(w / v) \mathrm{KOH}$ treatment for $1 \mathrm{~h}$ in a $90{ }^{\circ} \mathrm{C}$ water bath. The samples were then stained with $0.5 \%$ blue ink $\left(\operatorname{Hero}^{\circledR} 203\right.$, Shanghai, China) as described by Jing et al. [48]. At least 8 root fragments, $2 \mathrm{~cm}$ of each, were used to assess the intensity of DSE and AMF colonization, i.e., DSE hyphae and microsclerotia, and arbuscules and vesicles of AMF, under a compound-light microscope (OLYMPUS-BX31) $[49,50]$. If the presence of a microsclerotium or a dark septate hypha occurred in the microscopic field, the root sample was recorded as DSE colonization (AMF colonization was considered if an arbuscule or a vesicle was encountered.).

\subsection{DSE Isolation and Identification}

Thoroughly cleaned, fresh root samples were subjected to surface sterilization for 5 min each with $75 \%$ ethanol and $10 \% \mathrm{NaClO}$. The roots were then rinsed thrice with sterile distilled water, followed by air drying under sterile conditions [51]. These samples were then fragmented into $5 \mathrm{~mm}$ segments and deposited on both $1.8 \%$ potato dextrose agar (PDA, $200 \mathrm{~g}$ of potato extract and $20 \mathrm{~g}$ of dextrose per liter of water) and 1.8\% malt extract 
agar (200 g malt meal extract per liter of water, $\mathrm{pH}$ 6.4), supplemented with $50 \mathrm{mg} \mathrm{L}^{-1}$ of ampicillin. The samples were incubated in the dark for 30 days at $28^{\circ} \mathrm{C}$. Root samples were monitored on alternate days for the growth of new melanized fungal colonies, which were then transferred to fresh PDA slants.

The melanized fungal isolates were identified using both morphological and phylogenetic methods, as previously described [52]. Microscopic identification was carried out for the sporulated isolates, which confirmed the presence of conidia or conidiogenous cells [53]. Using the internal transcribed spacer, ITS1-5.8S-ITS2 rDNA, sequences of all fungal isolates were cloned using a primer set ITS1-F/ITS4 [54]. Phylogenetic analyses of all fungal isolates and similar ITS sequences retrieved from GenBank were carried out to identify their taxa [55].

\subsection{Root-Associated Fungal Assemblage Using Culture-Independent Methods}

Root-associated fungal assemblage was assessed using culture-independent methods based on the next-generation sequencing of the fungal ITS1. Briefly, four replicate samples of the two $O$. sinensis ecotypes with the maximum DSE colonization intensity were selected. The fresh roots were thoroughly cleaned and surface-sterilized as described above, then subjected to total DNA extraction using PowerPlant Pro DNA Isolation Kit (MOBIO Laboratories, Carlsbad, CA, USA) immediately or after refrigeration storage $\left(-86^{\circ} \mathrm{C}\right)$. The fungal universal primer ITS5-1737F/ITS2-2043R was used to amplify the ITS1, fusion with the barcodes, respectively [55].

PCR was carried out in triplicate for each sample (10 ng of DNA templates) in a $30 \mu \mathrm{L}$ reaction volume, with $15 \mu \mathrm{L}$ of Phusion High-Fidelity PCR Master Mix (New England Biolabs, Ipswich, MA, USA) and $0.2 \mu \mathrm{M}$ of e ach primer. The reactions were initiated at $98{ }^{\circ} \mathrm{C}$ for $1 \mathrm{~min}$. This was followed by 30 cycles of denaturation at $98^{\circ} \mathrm{C}$ with $10 \mathrm{~s}$ per cycle, annealing at $50{ }^{\circ} \mathrm{C}$ for $30 \mathrm{~s}$ and elongation at $72{ }^{\circ} \mathrm{C}$ for $60 \mathrm{~s}$. The final elongation step was carried out at $72{ }^{\circ} \mathrm{C}$ for $5 \mathrm{~min}$. Template DNA was excluded for the negative controls. PCR products were purified and separated by $2 \%$ agarose gel electrophoresis using a Qiagen gel-extraction kit (Thermo Scientific, Waltham, MA, USA). A TruSeq ${ }^{\circledR}$ DNA PCR-Free Sample Preparation Kit (New England Biolabs) was used to construct genomic DNA libraries, which were then sequenced by Illumina HiSeq 2000.

The clean data were subjected to OTUs analysis at $97 \%$ similarity. Species-effort curves were made to determine the sensitivity of the observed richness vs. the number of sequencing. For ascertaining the diversity and richness of root-associated fungal communities in the two O. sinensis ecotypes, $\alpha$ diversity indices such as Chao1, Shannon, Simpson and ACE were carried out in QIIME (Version 1.7.0). Additionally, $\beta$ diversity, including the un-weighted and weighted UniFrac distances, was studied using QIIME [55]. Sequencing results are available from the sequence read archive database, under GenBank accession number PRJNA593337.

\subsection{Statistical Analysis}

A $t$-test was carried out to analyze the difference among the two $O$. sinensis ecotypes, and differences were considered significant at $p<0.05$. The correlations between environmental variables and abundant classes were analyzed by Pearson's test using SPSS Software, version 19.0. PCoA was carried out using the weighted UniFrac distance. The $\alpha$ and $\beta$ diversity indices between the two batches were assessed using a paired $t$-test and Wilcoxon test using the stats $\mathrm{R}$ package (Version 2.15.3). All parameters in the dataset of AMF and DSE colonization intensities were screened to detect outliers and were excluded from the dataset in each comparison [56].

\section{Conclusions}

O. sinensis growing naturally forms large number of AMF structures and DSE colonization in MA and nMA. The endophytic fungal community structures of $O$. sinensis in nMA were more monotonous than those in the MA. The present study suggests that 
to accumulate more local endophytic fungi, such as Exophiala, presumably contribute to the reclamation of $O$. sinensis in extremely metal-polluted soils, e.g., metal mine tailings, as well as the expansion of its own community. However, further study on the potential biological effects of the detected fungi, as well as other functional bacteria or other environmental conditions (e.g., essential elements) in the survival and tolerance of $O$. sinensis in mine-tailing soil is required, and there is also a need for more information on the potential for phytoremediation, which may be used in the restoration of vegetation cover in heavy-metal-contaminated areas.

Author Contributions: Z.Z. and T.L. designed the research. Y.D. and M.Z. performed the experiments. X.L. and Y.X. analyzed the data. M.Z. wrote the manuscript. Z.Z. and T.L. revised the manuscript. All authors have read and agreed to the published version of the manuscript.

Funding: This research was financially co-supported by the National Natural Science Foundation of China, grant number 41761106, Applied Basic Research Programs of Yunnan Science and Technology Department, grant numbers 202001BB050001, 202001BB050065 and 018FY001-010 and "Double First-Class" University Project of Yunnan University, grant number C176282105.

Institutional Review Board Statement: Not applicable.

Informed Consent Statement: Not applicable.

Data Availability Statement: All data generated or analyzed during this study are included in this published article.

Conflicts of Interest: The authors declare no conflict of interest.

\section{References}

1. Buch, A.C.; Niemeyer, J.C.; Marques, E.D.; Silva-Filho, E.V. Ecological Risk Assessment of Trace Metals in Soils Affected by Mine Tailings. J. Hazard. Mater. 2020, 403, 123852. [CrossRef] [PubMed]

2. Briffa, J.; Sinagra, E.; Blundell, R. Heavy Metal Pollution in the Environment and Their Toxicological Effects on Humans. Heliyon 2020, 6, e04691. [CrossRef]

3. Ali, H.; Khan, E.; Sajad, M.A. Phytoremediation of Heavy Metals-Concepts and Applications. Chemosphere 2013, 91, 869-881. [CrossRef]

4. Liu, S.; Yang, B.; Liang, Y.; Xiao, Y.; Fang, J. Prospect of Phytoremediation Combined with Other Approaches for Remediation of Heavy Metal-Polluted Soils. Environ. Sci. Pollut. Res. 2020, 27, 16069-16085. [CrossRef] [PubMed]

5. Tordoff, G.; Baker, A.; Willis, A. Current Approaches to the Revegetation and Reclamation of Metalliferous Mine Wastes. Chemosphere 2000, 41, 219-228. [CrossRef]

6. Domka, A.M.; Rozpaądek, P.; Turnau, K. Are Fungal Endophytes Merely Mycorrhizal Copycats? The Role of Fungal Endophytes in the Adaptation of Plants to Metal Toxicity. Front. Microbiol. 2019, 10, 371. [CrossRef]

7. Liu, D.; Zhu, L.L.; Li, T.; Zhao, Z.W. Mutualism between Dark Septate Endophytes (DSEs) and Their Host Plants under Metal Stress: A Case Study. All Life 2021, 14, 667-677. [CrossRef]

8. Hui, F.; Liu, J.; Gao, Q.; Lou, B. Piriformospora indica Confers Cadmium Tolerance in Nicotiana tabacum. J. Environ. Sci. 2015, 37, 184-191. [CrossRef]

9. He, Y.; Fan, X.; Zhang, G.; Li, B.; Li, T.; Zu, Y.; Zhan, F. Effects of Arbuscular Mycorrhizal Fungi and Dark Septate Endophytes on Maize Performance and Root Traits under a High Cadmium Stress. S. Afr. J. Bot. 2019, 134, 415-423. [CrossRef]

10. Ultra, V.U., Jr.; Manyiwa, T. Influence of Mycorrhiza and Fly Ash on the Survival, Growth and Heavy Metal Accumulation in Three Acacia Species Grown in Cu-Ni Mine Soil. Environ. Geochem. Health 2021, 43, 1337-1353. [CrossRef] [PubMed]

11. Liu, B.; Wang, S.; Wang, J.; Zhang, X.; Shen, Z.; Shi, L.; Chen, Y. The Great Potential for Phytoremediation of Abandoned Tailings Pond Using Ectomycorrhizal Pinus sylvestris. Sci. Total Environ. 2020, 719, 137475. [CrossRef]

12. Gange, A.C.; Brown, V.K.; Sinclair, G.S. Vesicular-Arbuscular Mycorrhizal Fungi: A Determinant of Plant Community Structure in Early Succession. Funct. Ecol. 1993, 7, 616. [CrossRef]

13. Koziol, L.; Bever, J.D. Mycorrhizal Feedbacks Generate Positive Frequency Dependence Accelerating Grassland Succession. J. Ecol. 2018, 107, 622-632. [CrossRef]

14. Pérez, R.; Tapia, Y.; Antilén, M.; Casanova, M.; Vidal, C.; Santander, C.; Aponte, H.; Cornejo, P. Interactive Effect of Compost Application and Inoculation with the Fungus Claroideoglomus claroideum in Oenothera picensis Plants Growing in Mine Tailings. Ecotoxicol. Environ. Saf. 2020, 208, 111495. [CrossRef]

15. Veselkin, D.V.; Kupriynanov, A.N.; Manakov, A.; Betekhtina, A.A.; Prasad, M.N.V. Mycorrhizal Plants' Accelerated Revegetation on Coal Mine Overburden in the Dry Steppes of Kazakhstan. In Environmental Sustainability; Springer: New Delhi, India, 2014; pp. 265-280. [CrossRef] 
16. Durand, A.; Leglize, P.; Benizri, E. Are Endophytes Essential Partners for Plants and What Are the Prospects for Metal Phytoremediation? Plant Soil 2021, 460, 1-30. [CrossRef]

17. Yanqun, Z.; Yuan, L.; Schvartz, C.; Langlade, L.; Fan, L. Accumulation of Pb, Cd, Cu and Zn in Plants and Hyperaccumulator Choice in Lanping Lead-Zinc Mine Area, China. Environ. Int. 2004, 30, 567-576. [CrossRef] [PubMed]

18. Heckenroth, A.; Rabier, J.; Dutoit, T.; Torre, F.; Prudent, P.; Laffont-Schwob, I. Selection of Native Plants with Phytoremediation Potential for Highly Contaminated Mediterranean Soil Restoration: Tools for a Non-Destructive and Integrative Approach. J. Environ. Manag. 2016, 183, 850-863. [CrossRef] [PubMed]

19. Lei, D.; Duan, C. Restoration Potential of Pioneer Plants Growing on Lead-Zinc Mine Tailings in Lanping, Southwest China. J. Environ. Sci. 2008, 20, 1202-1209. [CrossRef]

20. Zhao, F.; Yang, Y.P. Reproductive Allocation in a Dioecious Perennial Oxyria sinensis (Polygonaceae) along Altitudinal Gradients. J. Syst. Evol. 2008, 46, 830-835. [CrossRef]

21. Li, Y.; Zu, Y.; Fang, Q.; Chen, H.; Schvartz, C. Characteristics of Heavy-Metal Tolerance and Growth in Two Ecotypes of Oxyria sinensis Hemsl. Grown on Huize Lead-Zinc Mining Area in Yunnan Province, China. Commun. Soil Sci. Plant Anal. 2013, 44, 2428-2442. [CrossRef]

22. Ruotsalainen, A.L.; Markkola, A.; Kozlov, M.V. Root Fungal Colonisation in Deschampsia flexuosa: Effects of Pollution and Neighbouring Trees. Environ. Pollut. 2007, 147, 723-728. [CrossRef] [PubMed]

23. Berthelot, C.; Blaudez, D.; Beguiristain, T.; Chalot, M.; Leyval, C. Co-Inoculation of Lolium perenne with Funneliformis mosseae and the Dark Septate Endophyte Cadophora sp. in a Trace Element-Polluted Soil. Mycorrhiza 2018, 28, 301-314. [CrossRef]

24. Gucwa-Przepióra, E.; Nadgórska-Socha, A.; Fojcik, B.; Chmura, D. Enzymatic Activities and Arbuscular Mycorrhizal Colonization of Plantago lanceolata and Plantago major in a Soil Root Zone under Heavy Metal Stress. Environ. Sci. Pollut. Res. 2015, 23, 4742-4755. [CrossRef] [PubMed]

25. Deram, A.; Languereau-Leman, F.; Howsam, M.; Petit, D.; Van Haluwyn, C. Seasonal Patterns of Cadmium Accumulation in Arrhenatherum elatius (Poaceae): Influence of Mycorrhizal and Endophytic Fungal Colonisation. Soil Biol. Biochem. 2008, 40, 845-848. [CrossRef]

26. Regvar, M.; Likar, M.; Piltaver, A.; Kugonič, N.; Smith, J.E. Fungal Community Structure under Goat Willows (Salix caprea L.) Growing at Metal Polluted Site: The Potential of Screening in a Model Phytostabilisation Study. Plant Soil 2009, 330, 345-356. [CrossRef]

27. Vergara, C.; Araujo, K.E.C.; Urquiaga, S.; Schultz, N.; Balieiro, F.D.C.; Medeiros, P.S.; Santos, L.A.; Xavier, G.R.; Zilli, J.E. Dark Septate Endophytic Fungi Help Tomato to Acquire Nutrients from Ground Plant Material. Front. Microbiol. 2017, 8, 2437. [CrossRef]

28. Andrade-Linares, D.R.; Grosch, R.; Restrepo, S.; Krumbein, A.; Franken, P. Effects of Dark Septate Endophytes on Tomato Plant Performance. Mycorrhiza 2010, 21, 413-422. [CrossRef]

29. Xu, R.; Li, T.; Shen, M.; Yang, Z.L.; Zhao, Z.-W. Evidence for a Dark Septate Endophyte (Exophiala pisciphila, H93) Enhancing Phosphorus Absorption by Maize Seedlings. Plant Soil 2020, 452, 249-266. [CrossRef]

30. Ruthrof, K.X.; Fontaine, J.; Hopkins, A.J.; McHenry, M.P.; O’Hara, G.; McComb, J.; Hardy, G.E.; Howieson, J. Potassium Amendment Increases Biomass and Reduces Heavy Metal Concentrations in Lablab purpureus after Phosphate Mining. Land Degrad. Dev. 2017, 29, 398-407. [CrossRef]

31. Addy, H.D.; Piercey, M.M.; Currah, R. Microfungal Endophytes in Roots. Can. J. Bot. 2005, 83, 1-13. [CrossRef]

32. Jumpponen, A.; Trappe, J.M. Dark Septate Endophytes: A Review of Facultative Biotrophic Root-Colonizing Fungi. New Phytol. 1998, 140, 295-310. [CrossRef]

33. Zhao, Z.-W.; Li, T. Dark Septate Endophytes and Their Ecological Function in Metal Mining. Sci. Sin. Vitae 2019, 49, 921-926. [CrossRef]

34. Zhang, Y.; Li, T.; Zhao, Z.-W. Colonization Characteristics and Composition of Dark Septate Endophytes (DSE) in a Lead and Zinc Slag Heap in Southwest China. Soil Sediment Contam. Int. J. 2013, 22, 532-545. [CrossRef]

35. Cao, G.-H.; He, S.; Chen, D.; Li, T.; Zhao, Z.-W. EpABC Genes in the Adaptive Responses of Exophiala pisciphila to Metal Stress: Functional Importance and Relation to Metal Tolerance. Appl. Environ. Microbiol. 2019, 85, e01844-19. [CrossRef]

36. Li, T.; Liu, M.; Zhang, X.; Zhang, H.; Sha, T.; Zhao, Z. Improved Tolerance of Maize (Zea mays L.) to Heavy Metals by Colonization of a Dark Septate Endophyte (DSE) Exophiala pisciphila. Sci. Total Environ. 2011, 409, 1069-1074. [CrossRef]

37. Wang, J.-L.; Jun-Ling, W.; Liu, G.-Y.; Smith, J.M.; Zhao, Z.-W. Unraveling the Role of Dark Septate Endophyte (DSE) Colonizing Maize (Zea mays) under Cadmium Stress: Physiological, Cytological and Genic Aspects. Sci. Rep. 2016, 6, 22028. [CrossRef] [PubMed]

38. Xiao, E.; Ning, Z.; Xiao, T.; Sun, W.; Qiu, Y.; Zhang, Y.; Chen, J.; Gou, Z.; Chen, Y. Variation in Rhizosphere Microbiota Correlates with Edaphic Factor in an Abandoned Antimony Tailing Dump. Environ. Pollut. 2019, 253, 141-151. [CrossRef]

39. Davis, E.C.; Franklin, J.B.; Shaw, A.J.O.; Vilgalys, R. Endophytic Xylaria (Xylariaceae) among Liverworts and Angiosperms: Phylogenetics, Distribution, and Symbiosis. Am. J. Bot. 2003, 90, 1661-1667. [CrossRef]

40. Wężowicz, K.; Rozpądek, P.; Turnau, K. Interactions of Arbuscular Mycorrhizal and Endophytic Fungi Improve Seedling Survival and Growth in Post-Mining Waste. Mycorrhiza 2017, 27, 499-511. [CrossRef]

41. Muthukumar, T.; Udaiyan, K.; Shanmughavel, P. Mycorrhiza in Sedges-An Overview. Mycorrhiza 2004, 14, 65-77. [CrossRef] 
42. Wagg, C.; Jansa, J.; Schmid, B.; van der Heijden, M.G.A. Belowground Biodiversity Effects of Plant Symbionts Support Aboveground Productivity. Ecol. Lett. 2011, 14, 1001-1009. [CrossRef] [PubMed]

43. Wagg, C.; Jansa, J.; Stadler, M.; Schmid, B.; van der Heijden, M.G.A. Mycorrhizal Fungal Identity and Diversity Relaxes Plant-Plant Competition. Ecology 2011, 92, 1303-1313. [CrossRef] [PubMed]

44. Xue, B.G.; Wu, L.S. Studies of Historical Data Concerning Exploitation of Silver (Lead)-Zinc Deposits in Yunnan Province and Some Opinions on Further Mineral Exploration. Miner. Depos. 2002, 21, 303-309. [CrossRef]

45. Yu, F.-K.; Huang, X.-H.; Duan, C.-Q.; He, S.-Z.; Zhang, G.-S.; Liu, C.-E.; Fu, D.-G.; Shao, H.-B. Impacts of Ageratina adenophora Invasion on Soil Physical-Chemical Properties of Eucalyptus Plantation and Implications for Constructing Agro-Forest Ecosystem. Ecol. Eng. 2014, 64, 130-135. [CrossRef]

46. Sun, S.; Zhang, J.; Cai, C.; Cai, Z.; Li, X.; Wang, R. Coupling of Non-Point Source Pollution and Soil Characteristics Covered by Phyllostachys edulis Stands in Hilly Water Source Area. J. Environ. Manag. 2020, 268, 110657. [CrossRef]

47. Watanabe, Y.; Itanna, F.; Izumi, Y.; Awala, S.K.; Fujioka, Y.; Tsuchiya, K.; Iijima, M. Cattle Manure and Intercropping Effects on Soil Properties and Growth and Yield of Pearl Millet and Cowpea in Namibia. J. Crop. Improv. 2019, 33, 395-409. [CrossRef]

48. Jing, Y.; Li, T.; Cui, H.; Li, L.; Allen, S.; Chen, L.; Li, Y.; Zhao, Z. Shifts in the Arbuscular Mycorrhizal Fungal Community Composition of Betula alnoides along Young, Middle-Aged Plantation and Adjacent Natural Forest. iFor. Biogeosci. For. 2020, 13, 447-455. [CrossRef]

49. McGonigle, T.P.; Miller, M.H.; Evans, D.G.; Fairchild, G.L.; Swan, J.A. A New Method Which Gives an Objective Measure of Colonization of Roots by Vesicular-Arbuscular Mycorrhizal Fungi. New Phytol. 1990, 115, 495-501. [CrossRef] [PubMed]

50. Olsrud, M.; Michelsen, A.; Wallander, H. Ergosterol Content in Ericaceous Hair Roots Correlates with Dark Septate Endophytes but Not with Ericoid Mycorrhizal Colonization. Soil Biol. Biochem. 2007, 39, 1218-1221. [CrossRef]

51. Silvani, V.; Fracchia, S.; Fernández, L.; Pérgola, M.; Godeas, A. A Simple Method to Obtain Endophytic Microorganisms from Field-Collected Roots. Soil Biol. Biochem. 2008, 40, 1259-1263. [CrossRef]

52. Xu, R.; Li, T.; Cui, H.; Wang, J.; Yu, X.; Ding, Y.; Wang, C.; Yang, Z.; Zhao, Z. Diversity and Characterization of Cd-Tolerant Dark Septate Endophytes (DSEs) Associated with the roots of Nepal Alder (Alnus nepalensis) in a Metal Mine Tailing of Southwest China. Appl. Soil Ecol. 2015, 93, 11-18. [CrossRef]

53. Barnett, H.L.; Hunter, B.B. Illustrated Genera of Imperfect Fungi. Mycologia 1972, 64, 930. [CrossRef]

54. White, T.J.; Bruns, T.; Lee, S.; Taylor, J.W. Amplification and Direct Sequencing of Fungal Ribosomal RNA Genes for Phylogenetics. In PCR Protocols: A Guide to Methods and Applications; Innis, M.A., Gelfand, D.H., Sninsky, J.J., White, T.J., Eds.; Academic Press, Inc.: New York, NY, USA, 1990.

55. Huang, Y.; Kuang, Z.; Wang, W.; Cao, L. Exploring Potential Bacterial and Fungal Biocontrol Agents Transmitted from Seeds to Sprouts of Wheat. Biol. Control 2016, 98, 27-33. [CrossRef]

56. Kutner, M.H.; Nachtsheim, C.J.; Neter, J.; Li, W. Diagnostics and Remedial Measures Applied Linear Statistical Models, 5th ed.; McGraw-Hill/Irwin: New York, NY, USA, 2004; p. 108. ISBN 0-07-238688-6. 